\title{
Effects of Nitrogen Application Levels on Leaf Yield and Nutrient Uptake of Moringa oleifera under Mowing Condition
}

\author{
Lina Huang ${ }^{1, a}$, Shimin Cheng ${ }^{1, b}$, Zhenrong Yang ${ }^{1, c}$, Zengxian Zhao ${ }^{1, d}$, Zisi \\ $\mathrm{Xie}^{1, \mathrm{e}}$ and Shouxing Wei $\mathrm{i}^{1, \mathrm{f}^{*}}$ \\ ${ }^{1}$ Tropical Crops Genetic Resources Institute, Chinese Academy of Tropical Agricultural \\ Sciences(CARTA), Danzhou,571737,China

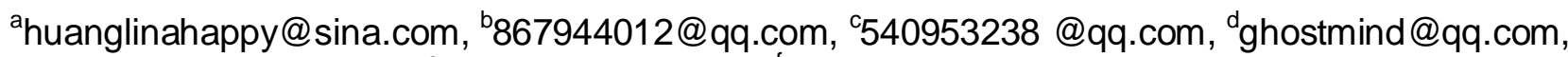 \\ e64043545@qq.com, 'shouxingwei@163.com
}

Keywords: Mowing; Nitrogen Application Level; Moringa Oleifera; Dry Matter Accumulation; Nutrient Uptake

\begin{abstract}
Taking Indian Moringa oleifera as the object, using pot experiment, setting different nitrogen application levels under the mowing conditions, the most appropriate nitrogen fertilizer application was determined by analysing the effects of different nitrogen application levels on the dry matter and uptake of nitrogen, phosphorus and kalium. The results showed that after mowing five times, when the application rates of phosphorus and kalium and are both $250 \mathrm{mg} \mathrm{kg}-1$, the yield of Moringa oleifera leaves increased significantly with the increase of nitrogen application rate. The highest yield was $595.67 \mathrm{~g} /$ tree when the nitrogen application rate is $300 \mathrm{mg} \mathrm{kg}-1$. It is favorable for dry matter accumulation of Moringa oleifera, especially leaf dry matter when the nitrogen application rate is $300 \mathrm{mg} \mathrm{N} \mathrm{/} \mathrm{kg,} \mathrm{and} \mathrm{increases} \mathrm{its} \mathrm{absorption} \mathrm{of} \mathrm{phosphorus} \mathrm{and} \mathrm{potassium.}$ Therefore, in the present experiment condition, when the dosage of nitrogen, phosphorus and potassium in the cultivation of Moringa oleifera is $300 \mathrm{mg} \mathrm{kg}-1,250 \mathrm{mg} \mathrm{kg}-1,250 \mathrm{mg} \mathrm{kg}-1$ respectively, it was beneficial to improve the yield and nutrient uptake of Moringa oleifera.
\end{abstract}

\section{Introduction}

Moringa oleifera, a perennial deciduous woody vegetable and oil plant, rich in nutrients, is a medicinal and edible plant, known as the "magic tree" and "mother's best friend"[1-2]。At present, the research on Moringa oleifera at home and abroad mainly focuses on the development and utilization of medicinal value and active ingredients. However, the research on cultivation and management of Moringa oleifera is insufficient, leading to the lack of scientific and efficient cultivation and management techniques of Moringa plantation.[3-6] Therefore, how to improve the yield and nutrient content of Moringa oleifera through effective field cultivation and management measures has become an urgent problem to be solved in production. Fertilization is one of the important contents of field cultivation and management measures, and it is an important part of scientific and reasonable planting of Moringa oleifera. However, due to that less research has been done on this area at present, it is difficult to determine the scientific and efficient rational fertilization formula according to its growth situation.

Studies have shown that when the Moringa seedlings lack of nitrogen, the symptoms appear the most obviously. The initial lack of nitrogen will make the plant light yellow and short, the leaves small and weak growth, which will not appear if kalium is insufficient. Among them, the differences of net height of seedling and stem growth are significant when the nitrogen is insufficient. Therefore, nitrogen is the major element which determines the elongation and stem thickening of Moringa oleifera, while the effect of kalium deficiency on leaf number of Moringa oleifera is not obvious.

The results showed that nitrogen, phosphorus, kalium and calcium deficiency had a certain effect on the growth of Moringa oleifera in seedling stage, but the influence degrees were different, with the greatest impact of nitrogen deficiency[7-8]. The above research is carried out under the condition that the leaves of Moringa are not mowed, but in the actual production, leaves are the 
mainly useful parts, which need to be mowed continuously. Therefore, the effect of different nitrogen fertilizer levels on the growth of Moringa oleifera and the nutrient uptake of nitrogen, phosphorus and kalium under the mowing condition was studied by single factor experiment. Also, the requirement of nitrogen utilization of Moringa oleifera was studied in order to provide the theoretical basis for determining the suitable nitrogen fertilizer amount and establishing reasonable fertilization formula of Moringa oleifera.

\section{Experimental Material}

Experimental Crop: Moringa oleifera, whose seedlings were provided by the Vegetable Research Institute, Tropical Crops Genetic Resources Institute, Chinese Academy of Tropical Agricultural Sciences. The average seedling height before planting was $14.00 \mathrm{~cm}$, stem $2.30 \mathrm{~mm}$.

Experimental Substrate : The latosol and coir pith were mixed at the volume ratio of 2:1. The $\mathrm{pH}$ value of cultivation substrate was 4.98. The content of organic matter was $8.74 \mathrm{~g} / \mathrm{kg}$, available nitrogen $118.37 \mathrm{mg} / \mathrm{kg}$, available phosphorus $7.32 \mathrm{mg} / \mathrm{kg}$, and rapidly available kalium $90.83 \mathrm{mg} / \mathrm{kg}$.

Experimental Fertilizer: urea (N 46\%), calcium magnesium phosphate (P2O5 12.5\%), potassium chloride (containing 60\% K2O).

Experimental Pot: the upper diameter was $30 \mathrm{~cm}$, the lower diameter was $24 \mathrm{~cm}$ and the height was $34 \mathrm{~cm}$. The substrate was $10 \mathrm{~kg} /$ pot.

\section{Experimental Method}

We took single-factor experiment, and the nitrogen level was the factor. The soil nitrogen content were $100 \mathrm{mg} \mathrm{N} / \mathrm{kg}, 200 \mathrm{mg} \mathrm{N} / \mathrm{kg}, 100 \mathrm{mg} \mathrm{N} / \mathrm{kg}$. The soil P2O5 and K2O content were both $250 \mathrm{mg} / \mathrm{kg}$, which were set as control groups with non-fertilization, were recorded as N1, N2, N3, CK. The fertilizer was applied 6 times, once every two weeks in the form of water and fertilizer. In this study, there were four treatment groups, including three different experimental groups and a blank control group. Each tree is a repeat, with 15 trees in an experimental group. The experiment was conducted from August 2016 to November 2016 at the fifth teams greenhouse test base in Tropical Crops Genetic Resources Institute, Chinese Academy of Tropical Agricultural Sciences. They were planted, transplanted seedlings, and fertilized according to the treatment. They were watered and the agriculture chemical were sprayed regularly to guarantee the the normal growth of plants. The trees were fertilized once every two weeks at 6 times according to the test plan. The Moringa oleiferas were mowed when their overall growth height reached to stubble height standards $(100 \mathrm{~m})$. We weighed and recorded the biomass of each fresh weight under mowing, drying and pulverizing, to be tested. The samples were pulverized and digested with $\mathrm{H} 2 \mathrm{SO} 4-\mathrm{H} 2 \mathrm{O} 2$. The $\mathrm{N}$ was measured through indigo phenol blue colorimetric method. The $\mathrm{P}$ was measured through Mo-Sb colorimetric method and the K was measured through flame spectrophotometry method[9].

\section{Data Calculation and Processing}

The test data were processed and analysed by Excel 2007 and SPSS 13.0 software.

\section{Result and Analysis}

\section{Effects of Nitrogen Application on Leaf Yield}

As shown in Table 1, compared with CK, the application of nitrogen fertilizer under mowing conditions can significantly improve the yield of Moringa oleifera. The leaves fertilized by nitrogen output from the first time mowing to the fifth are respectively 2.67 times, 1.44 times, 2.84 times, 2.37 times, 3.11 times of CK, raising the total yield to $144.64 \%$. Comparing the different nitrogen application levels, we could know that with the increase of mowing times, the effect of nitrogen application on the yield of Moringa oleifera was more obvious. At the fifth mowing, the leaf yield of Moringa oleifera showed significant difference with the nitrogen application level. In summary, the results showed that $\mathrm{N} 3$ had the highest treatment rate of $595.67 \mathrm{~g} /$ tree. It could be seen that when the level of phosphorus and potassium were consistent, the yield of Moringa oleifera increased significantly with the increase of nitrogen application rate, and the highest yield was 300 $\mathrm{mg} \mathrm{N} / \mathrm{kg}$ in this experiment. 
Table 1 Effects of nitrogen application on leaf yield ( $\mathrm{g} /$ tree $)$

\begin{tabular}{|c|c|c|c|c|}
\hline \multirow{2}{*}{ Times } & \multicolumn{4}{|c|}{ Experimental Treatment } \\
\cline { 2 - 5 } & CK & N1 & N2 & N3 \\
\hline 1st & $5.12 \pm 0.07 \mathrm{c}$ & $17.52 \pm 0.70 \mathrm{a}$ & $8.23 \pm 0.60 \mathrm{~b}$ & $15.27 \pm 1.52 \mathrm{a}$ \\
\hline 2nd & $46.53 \pm 3.08 \mathrm{~b}$ & $54.51 \pm 2.24 \mathrm{~b}$ & $70.04 \pm 2.27 \mathrm{a}$ & $76.04 \pm 2.08 \mathrm{a}$ \\
\hline 3rd & $28.06 \pm 2.62 \mathrm{c}$ & $71.27 \pm 4.27 \mathrm{~b}$ & $79.07 \pm 5.59 \mathrm{ab}$ & $88.23 \pm 2.61 \mathrm{a}$ \\
\hline 4th & $61.97 \pm 1.65 \mathrm{c}$ & $118.76 \pm 4.91 \mathrm{~b}$ & $163.79 \pm 6.78 \mathrm{a}$ & $158.96 \pm 1.11 \mathrm{a}$ \\
\hline 5th & $59.08 \pm 1.42 \mathrm{~d}$ & $103.64 \pm 1.88 \mathrm{c}$ & $190.77 \pm 8.48 \mathrm{~b}$ & $257.18 \pm 6.36 \mathrm{a}$ \\
\hline Total & $200.74 \pm 7.41 \mathrm{~d}$ & $365.70 \pm 9.51 \mathrm{c}$ & $511.91 \pm 2.42 \mathrm{~b}$ & $595.67 \pm 5.98 \mathrm{a}$ \\
\hline
\end{tabular}

(Note: The values in the table represent the mean \pm standard error, and the difference between the lowercase letters of the peer is significant $(\mathrm{P} \leq 0.05)$. The multiple comparison used Duncan's new differential method. Hereinafter inclusive.)

\section{The Influence on the Dry Matter Accumulation of Moringa Oleifera}

The application of nitrogen fertilizer can significantly increase the dry matter accumulation of Moringa oleifera according to the analysis of the dry matter of different parts.(table 2). The average increase of dry matter of whole Moringa oleifera was $90.35 \%$. The dry matter of leaf, root, stem and other parts also increased significantly. Further analysis showed that the dry matter quality of the leaves increased significantly with the increase of nitrogen application rate, while the root showed the opposite trend, that is, the dry matter accumulation decreased significantly with the increase of nitrogen application rate. N1, N3 treatments showed that the dry matter of stem was not significantly different and were both higher than N2 treatment, which may be due to when low nitrogen stress was soil of $100 \mathrm{mg} \mathrm{N} / \mathrm{kg}$, Moringa oleifera roots grew rapidly, resulting in mass dry matter accumulation. $300 \mathrm{mg} \mathrm{N} / \mathrm{kg}$ soil nitrogen application rate can promote the growth of leaves rapidly, thereby increasing leaf yield. Therefore, the nitrogen application level of $100 \mathrm{mg} \mathrm{N} / \mathrm{kg}$ or $300 \mathrm{mg} \mathrm{N} / \mathrm{kg}$ can promote the accumulation of dry matter of Moringa oleifera, especially 300mg N $/ \mathrm{kg}$ is more conducive to leaf dry matter accumulation.

Table 2 Effect of nitrogen application on dry matter accumulation of Moringa oleifera

\begin{tabular}{|c|l|l|l|l|}
\hline \multirow{2}{*}{ Parts } & \multicolumn{4}{|c|}{ Experimental Treatment } \\
\cline { 2 - 5 } & CK & $\mathrm{N} 1$ & $\mathrm{~N} 2$ & $\mathrm{~N} 3$ \\
\hline Leaf & $34.18 \pm 1.00 \mathrm{~d}$ & $60.96 \pm 1.58 \mathrm{c}$ & $80.78 \pm 0.81 \mathrm{~b}$ & $90.02 \pm 0.80 \mathrm{a}$ \\
\hline Root & $13.25 \pm 0.65 \mathrm{c}$ & $34.87 \pm 0.97 \mathrm{a}$ & $15.54 \pm 0.59 \mathrm{~b}$ & $12.08 \pm 0.48 \mathrm{c}$ \\
\hline Stem & $22.14 \pm 0.63 \mathrm{c}$ & $37.18 \pm 1.30 \mathrm{a}$ & $30.70 \pm 0.82 \mathrm{~b}$ & $35.13 \pm 0.47 \mathrm{a}$ \\
\hline Plant & $69.57 \pm 1.80 \mathrm{c}$ & $133.02 \pm 1.57 \mathrm{a}$ & $127.02 \pm 1.01 \mathrm{~b}$ & $137.23 \pm 0.76 \mathrm{a}$ \\
\hline
\end{tabular}

Effect on Nutrient Uptake of Moringa oleifera

The results in Tab.3 showed that the application of nitrogen fertilizer in the mowing condition could significantly improve the absorption of nitrogen, phosphorus and kalium in Moringa oleifera, which were 2.41 times, 2.42 times and 1.52 times of CK treatment respectively. In terms of nitrogen uptake, the nitrogen uptake of Moringa oleifera increased significantly with the increase of nitrogen application rate, and the $\mathrm{N}$ uptake was the highest in $\mathrm{N} 3$ treatment, which was $94.55 \%$ and $56.85 \%$ higher than N1 treatment and N2 treatment respectively. With the increase of nitrogen application rate of Moringa oleifera, The phosphorus uptake increased first and then decreased, and the highest nitrogen uptake was $\mathrm{N} 2$ treatment. It showed no significant difference between $\mathrm{N} 2$ and N3 treatments about kalium, which were significantly higher than those of N1 treatment. It can be seen that the increase of nitrogen application is beneficial to the uptake of nitrogen and potassium for Moringa oleifera. 
Table 3 Effect of nitrogen application on nutrient uptake of Moringa oleifera

\begin{tabular}{|c|c|c|c|c|}
\hline \multirow{2}{*}{ Nutrition } & \multicolumn{4}{|c|}{ Experimental Treatment } \\
\cline { 2 - 5 } & $\mathrm{CK}$ & $\mathrm{N} 1$ & $\mathrm{~N} 2$ & $\mathrm{~N} 3$ \\
\hline $\mathrm{N}$ & $0.912 \pm 0.013 \mathrm{~d}$ & $1.574 \pm 0.011 \mathrm{c}$ & $1.952 \pm 0.016 \mathrm{~b}$ & $3.062 \pm 0.055 \mathrm{a}$ \\
\hline $\mathrm{P}$ & $0.240 \pm 0.006 \mathrm{c}$ & $0.517 \pm 0.012 \mathrm{~b}$ & $0.689 \pm 0.021 \mathrm{a}$ & $0.539 \pm 0.010 \mathrm{~b}$ \\
\hline $\mathrm{K}$ & $2.768 \pm 0.040 \mathrm{c}$ & $3.999 \pm 0.056 \mathrm{~b}$ & $4.348 \pm 0.040 \mathrm{a}$ & $4.301 \pm 0.026 \mathrm{a}$ \\
\hline
\end{tabular}

\section{Discussion and Conclusion}

Studies have found that on the condition that the application of phosphorus and kalium fertilizer did not change, the application of nitrogen fertilizer can significantly promote the growth of plant leaves and accumulation of dry matter of Moringa oleifera [7,10]. The experiment also showed that when the amount of phosphorus and kalium fertilizer used were the same, different concentrations of nitrogen treatment had different effects on the Moringa oleifera.

The application of nitrogen had significant effects on the growth of Moringa oleifera, and when the application of nitrogen was 300mg kg-1, the yield of the leaves, the quality of dry matter and the growth of Moringa oleifera were all the best. In addition, the effect of nitrogen on different parts of Moringa oleifera was also different, which was shown by the dry matter accumulation of different parts of Moringa oleifera. In this experiment, the dry matter accumulation of leaves was highest at nitrogen application level of $300 \mathrm{mg} \mathrm{N} / \mathrm{kg}$ soil, while the dry matter accumulation of roots was the highest at $100 \mathrm{mg} \mathrm{N} / \mathrm{kg}$ soil.

In the process of growth of Moringa oleifera, fertilization is one of the most important links. Through the scientific fertilization management, can ensure the adequate supply of Moringa nutrient, while the growth of Moringa oleifera trees, flowering and results have a positive effect, increase seed yield and improve its quality [7-8,11]. According to the results of this experiment, the nitrogen has significant facilitation to the growth and nutrient uptake of Moringa oleifera under the mowing conditions. When the amount of nitrogen application was $100-300 \mathrm{mg} \mathrm{kg}-1$, and the amounts of phosphorus and kalium were $250 \mathrm{mg} \mathrm{kg}$-1, the yield of leaves and the dry matter accumulation of Moringa oleifera was increased greatly. When the amount of nitrogen application was $300 \mathrm{mg} \mathrm{kg}-1$, the uptake of nitrogen and kalium by Moringa oleifera was the highest. This experiment only studied the effect of nitrogen on the growth and nutrient uptake of Moringa oleifera. In order to provide a really complete scientific and reasonable fertilization plan for the processing of Moringa oleifera, the effects of combined application of nitrogen, phosphorous and kalium or other factors still need further studies.

\section{Reference}

[1] D. Wu, Z. H. Cai, Y. X. Wei, etc. Research Advances in Moringa as a New Plant Protein Feed[J].Chinese Journal of Animal Nutrition, 2013, 25(3):1-9.

[2] C. F. Liu and G. H. Li. Actuality of Study on Moringa Oleifera and their Exploitive Foreground[J].Journal of Yunnan Tro ,2002, 25(3): 20-24.

[3] Homa Manaheji, Soheila Jafari, Jalal Zaringhalam. Analgesic effects of methanolic extracts of the leaf or root of Moringa oleifera on complete Freund's adjuvant-induced arthritis in rats[J].Journal of Chinese Integrative Medicing,2011,9(2):216-222.

[4] Popoola J 0, Obembe O O. Local knowledge, use pattern and geographical distribution of Moringa oleifera Lam. (Moringaeeae)in Nigeria[J]. J Ethnopharmacol, 2013, 150(2): 682-691.

[5] B. Wu and Y. Zheng. Research on the Modification of Moringa Oleifera Seed for Bio-Adsorption of Cr(VI) [J].Environmental Pollution \& Control, 2013, 35(12):64-67.

[6] Hussain S, Malik F, Mahmood S. Review: An exposition of medicinal preponderance of Moringaoleifera(Lank.)[J].Pak J Pharm Sc, 2014, 27(2):397-403.

[7] L. Li, Z. H. Yin and H. J. Ya. Influence of N, P, K, Ca Deficiency on Growth of Moringa oleifera Lam Seedlings[J].Chinese Agricultural Science Bulletin, 2015, 31(16): 52-56. 
[8] D. Zhang, H. Y. Long, Y. P. Zhang, etc. Effects of Planting Density and Cultivation Technology on Agronomic Characters of Moringa oleifera in Dry-hot Valley of Yuanmou[J].Southwest China Journal of Agricultural Sciences, 2014, (05): 1870-1873.

[9] R. K. Lu. Agrochemistry Analysis Methods[M].Beijing: China Agriculture Science and Technique Press, 2000

[10] L. L. Kou, M. J. Geng, B. Q. Xiang, etc. The Effect of N, P and K Fertilizer on the Nutrient Uptake of Smooth Vetch[J].Hubei Agricultural Sciences, 2011, 17: 3522-3525.

[11] Y. Q. Xu. The Studies on Fertillzation Effect and Nutrient Diagnoses on Moringa SP. Seedings[D].Beijing: Chinese Academy of Forestry Sciences, 2010: 23-24 . 